\title{
Effect of Nasal Septoturbinoplasty on Nasality or Acoustic Parameters
}

\author{
Hee Sung Park ${ }^{1}$, Young Ae Kang ${ }^{1}$, Jun Xu ${ }^{1}$, Ruining Han ${ }^{1}$, Ki-Sang Rha ${ }^{1,2}$, and Yong Min Kim ${ }^{1,2}$ \\ ${ }^{1}$ Department of Otorhinolaryngology-Head and Neck Surgery, ${ }^{2}$ Research Institute for Medical Science, \\ Chungnam National University School of Medicine, Daejeon, Korea
}

비중격 성형술 후 비음치 및 음향학적 특징의 변화

박희성 ${ }^{1} \cdot$ 강영애 $^{1} \cdot$ 허 준 $^{1} \cdot$ 한예녕 $^{1} \cdot$ 나기상 ${ }^{1,2} \cdot$ 김용민 $^{1,2}$

충남대학교 의학전문대학원 이비인후과학교실, ${ }^{1}$ 의학연구소 ${ }^{2}$

Received January 27, 2016

Revised April 16,2016

Accepted April 20, 2016

Address for correspondence

Yong Min Kim, MD

Department of Otorhinolaryngology-

Head and Neck Surgery,

Chungnam National University

School of Medicine,

282 Munhwa-ro, Jung-gu,

Daejeon 35015, Korea

Tel $+82-42-280-7696$

Fax $+82-42-253-4059$

E-mail entkym@cnu.ac.kr
Background and Objectives The purpose of this study was to compare the nasality and acoustic variables of control subjects and those of patients with deviated nasal septum (DNS), preoperatively and postoperatively.

Subjects and Method Twenty patients who underwent septoturbinoplasty (DNS group) and ten control subjects (control group) who did not complain of nasal obstruction or did not show any anatomic or pathologic abnormality were selected. Performed for these subjects were acoustic rhinometry, rhinomanometry, nasality test and long-term average spectrum analysis of nasal sound sentence. Data were collected and analyzed prior to and 4 weeks after the surgery. Results In DNS group, the volume of nasal cavity was significantly increased and the nasal resistance was decreased significantly after operation. There were no statistically significant differences in the nasality of all sentences in the DNS group compared to those in the preoperative and the postoperative group. However, alternations of several acoustic variables in the final consonant were detected.

Conclusion Alternation of nasality and acoustic variables was observed after septoturbinoplasty, however, the changes of nasal resistance have been shown to contribute to the results. Korean J Otorhinolaryngol-Head Neck Surg 2016;59(7):510-6

Key Words Acoustics $\cdot$ Nasal septum $\cdot$ Turbinate $\cdot$ Voice.

\section{서 론}

음성의 특색은 성대에서 발생한 음향학적 요소와 기도의 공명에 의해 결정된다. ${ }^{1)}$ 성대에서 생성된 음향은 구개인두협 부에 이르러 비강과 구강으로 나뉘어져 구강음과 비강음을 각각 형성하게 되며, 각각의 소리는 연구개의 해부학적, 기능적 상태에 따라 비율이 결정이 된다. ${ }^{2)}$ 비음치(nasalance score) 는 비강 음향에너지를 비강과 구강 음향에너지의 합으로 나 눈 값을 의미한다. 따라서, 비강으로의 기류량이 증가함에 따라 비음치는 더 커질 것으로 예상할 수 있다. ${ }^{2,3)}$ 하지만, 만 성 비부비동염 환자를 대상으로 시행한 연구에서 코막힘이
더 심할 것으로 추측되는 환자군이 정상 대조군에 비해 비음 치가 통계적으로 의미 있는 차이를 보이지 않았으며, 환자군 에서 비부비동내시경 수술 후 3 개월에 측정한 비음치는 수 술 전에 비해 통계적으로 유의하게 증가함을 보여 환자 개개 인의 코막힘의 변화가 비음치에 더 큰 영향을 미치는 것을 알 수 있었다. ${ }^{4)}$

비중격 성형수술을 시행한 환자를 대상으로 시행한 선행 연구에서 비음문장에 대한 비음치는 수술 전에 비해 수술 후에 증가하는 양상을 보였지만 통계적으로 의미 있는 결과 를 얻지 못하였다. 하지만, 스펙트럼 분석에서 비음 /angang/의 제1포먼트(formant 1)의 변화가 술 전에 비해 술 후에 통계적 
으로 의미 있는 감소를 보여 비중격만곡증의 수술은 비음치 와 포먼트를 제한적으로 변화시킬 수 있다고 하였다. ${ }^{5}$

비강 내에서 코막힘을 일으키는 가장 중요한 부위는 비밸 브 부위이며, 비밸브의 단면적을 가장 많이 변화시킬 수 있 는 수술 중 하나가 비중격성형술과 하비갑개 수술이다. 그동 안 만성 비부비동염 환자의 수술 전 후의 비음치의 변화를 관 찰한 연구는 다수 보고되었지만, 상대적으로 비밸브 부위를 확장시키는 데 중요한 역할을 하는 비중격 성형술과 하비갑 개수술 전후의 비음치 변화와 음향학적 변수를 분석한 연구 는 상대적으로 적다. 따라서, 본 연구에서는 정상 대조군과 비 중격만곡증 환자를 대상으로 비음치와 음향학적인 변수들 을 비교하고자 하였고, 비중격만곡증 환자에서 비중격 교정술 과 하비갑개 축소수술 후 비음치와 음향학적 변수를 수술 전과 비교하고자 하였다.

\section{대상 및 방법}

\section{대 상}

2014년 9월부터 2015년 5월까지 병원에서 비중격만곡증으 로 비중격성형술과 하비갑개 축소술을 받은 20명을 대상으 로 수술 전 및 수술 후 4주에 음향비강통기도 검사, 비강통기 도 검사 및 비음치검사를 시행하였다. 환자의 평균 연령은 30.75세였고 모두 남성이었다(Table 1). 수술은 동일한 1인의 시술자에 의해 진행되었다. 대조군으로는 같은 기간 동안 코 막힘의 증상이 없고 신체검사와 부비동 단순 X-ray 검사에서 비부비동염 및 비중격만곡증이 없는 정상 성인 남성 10명을 모집하여 환자군과 동일한 검사를 실시하였다. 대조군의 평 균 연령은 30.2세였고, 남녀의 해부학적 구조물의 차이로 인 한 공명영향을 최소화하기 위하여 대상자를 단일 성별(남성) 로만 모집하였다(Table 1).

\section{비강통기도 검사}

비강통기도 검사는 Eccovision Acoustic Rhinometer(Model AR-1003; Hood Laboratories, Pembroke, MA, USA)를 이 용하여 비강 내 분비물과 가피를 조심스럽게 제거한 후 시행 하였다. 비강의 전체 용적을 구하기 위해 음향 비강통기도 검 사를 이용하여 비공으로부터 후방 $7 \mathrm{~cm}$ 까지의 비강 용적을 양측 비공에서 각각 구한 후 더하여 전체 비강체적을 구하였 다. 비저항은 rhinomanometry를 이용하여 $150 \mathrm{~Pa}$ 에서 측정 하였으며 좌, 우를 각각 따로 잰 후 총 비저항을 구하는 공식 에 따라 흡기 시와 호기 시의 비저항 값을 계산하였다.

\section{비음치 검사}

비음치를 측정하기 위해 Nasometer II, model 6450(KayPentax Inc., Montvale, NJ, USA)으로 Park 등히이 사용한 문 장을 사용하였다. 문장은 전체 문장 중 비음(nasal consonants) 비율에 따라, 비음 $0 \%$ 인 구강음 문장(oral sentence), 비음 $31 \%$ 인 구강비음 문장(oro-nasal sentence), 비음 100\%인 비음 문 장(nasal sentence)으로 총 3가지 종류이다. 구강음 문장은 고모음(high vowel)이 27\%로 구성된 33음절이고, 구강비음 문장은 고모음이 $27 \%$ 인 37 음절의 의미 연결이 되는 문단으 로 구성되어 있으며, 비음 문장은 24음절로 어절 반복 형식 으로 이루어져 있다.

모든 녹음은 방음문이 설치된 조용한 방에서 이루어졌으 며 대상자를 편안한 의자에 앉히고 나조메타의 격판(plate) 이 코와 입술의 중간 지점인 인중에 수평이 되도록 위치시키 고 대상자의 머리를 바른 자세로 고정시키기 위해 녹음문장 을 프린트 하여 대상자 정면에 세워두어 보고 읽게 하였다. 녹 음 에러를 방지하기 위하여 나조메타 작동 시 4시간마다 보정 (calibration)을 하였으며 사전검사로 파열음과 비음 음절을 녹음하여 비음곡선 분포양상을 실시간으로 확인하여 분포 양상이 틀려지면 4시간 이전이라도 재보정 작업을 하였다.

Table 1. Comparison of nasal cavity, nasal resistance, nasalance

\begin{tabular}{lccc} 
& Control group & \multicolumn{2}{c}{ DNS group } \\
\cline { 3 - 3 } & & Preoperative & Postoperative \\
\hline Age & $30.2 \pm 5.33$ & $30.75 \pm 11.74$ & 100 \\
Sex $(\%$ of male $)$ & 100 & $17.05 \pm 5.33$ & $21.98 \pm 3.70$ \\
Total volume $\left(\mathrm{cm}^{3}\right)$ & $21.72 \pm 4.39$ & & \\
Total resistance $\left(\mathrm{Pa} \mathrm{s} / \mathrm{cm}^{3}\right)$ & & $0.95 \pm 0.50$ & $0.49 \pm 0.39$ \\
$\quad$ Inspiration & $0.38 \pm 0.37$ & $1.03 \pm 0.46$ & $0.67 \pm 0.57$ \\
$\quad$ Expiration & $0.41 \pm 0.39$ & & $13.31 \pm 5.69$ \\
Nasalance score & & $13.88 \pm 7.87$ & $37.81 \pm 4.53$ \\
$\quad$ Oral sentence & $9.4 \pm 3.13$ & $38.5 \pm 4.72$ & $64.56 \pm 4.08$ \\
$\quad$ Oronasal sentence & $34.6 \pm 4.70$ & $62.88 \pm 4.54$ & \\
$\quad$ Nasal sentence & $59.2 \pm 5.33$ & &
\end{tabular}

DNS: deviated nasal septum 
스펙트럼 분석을 위하여 나조메타로 녹음한 동일한 문장 을 CSL(computer speech lab; KayPentax Inc., Montvale, $\mathrm{NJ}, \mathrm{USA}$ 로 다시 녹음하였다. 마이크는 입으로부터 $10 \mathrm{~cm}$ 내외에 유지시켜, 90 도 각도로 고정하였으며 단일지향성 다이 나믹 마이크(Shur 48; Shur Inc., Niles, IL, USA)를 사용하여 PRE-amplification system(creative SB audiogy2 ZS)을 거 쳐 녹음하였으며 표본추출률(sampling)은 $50000 \mathrm{~Hz}$, 양자 화(quantization)는 $16 \mathrm{bit}$ 로 하였다.

모든 환자들은 수술 전에 한 번, 그리고 수술 후 4주째에 비 음치를 측정하였다.

비음 문장의 long term average spectrum(LTAS)의 분석

비중격 성형수술 전후의 비음치에 변화를 가져오는 주파 수대역을 알아보기 위하여 CSL로 녹음된 비음 문장을 대상 으로 Praat(5.3.8; University of Amsterdam, Amsterdam, the Netherlands) 프로그램을 사용하여 장구간평균스펙트럼 분석으로 스펙트럼 기울기관련 변수들과 포먼트(formant) 및 밴드윗드(bandwidth) 및 적률변수를 측정하였다.

LTAS 분석은 0 8000 Hz까지의 전체 구간에서의 최소값 (min), 최대값(max), 기울기(slope)를 분석하였고, 비음의 에너 지가 저주파수대 $(1000 \mathrm{~Hz}$ 이하)에 존재하므로 세부적으로 0 500 Hz, 501 1000 Hz에서도 측정하였다. 즉, 총 3구간의 주파수대역 $(0 \sim 8000 \mathrm{~Hz}, 0 \sim 500 \mathrm{~Hz}, 501 \sim 1000 \mathrm{~Hz})$ 에서 최소 값(min), 최대값(max), 기울기(slope)를 측정하였다(Fig. 1). LTAS 분석 절차는 비음문장의 첫 음성신호에서부터 끝 음 성신호까지를 선택하여 공명의 특성을 다 포착하기 위해 $\mathrm{de}^{-}$ emphasis filtering을 거치지 않고 Hanning window를 쓰워 pre-emphasis filtering 처리 후 푸리에 변환(FFT)을 통해 $\operatorname{Ltas}\left(1-\mathrm{to}^{-1}\right)$ 변환하였다.

비음 문장 중 종성 자음 $/ \mathrm{m} /, / \mathrm{n} /, / \mathrm{ng} /$ 에 대한 스펙트럼 분 석을 실시하여 각 음소별 포먼트(formant), 밴드윗드(bandwidth) 그리고 무게중심(centre of gravity), 왜도(skewness), 첨도(kurtosis), 중앙적률(central moment)로 구성된 적률변 수를 측정하였다(Fig. 2). 포먼트는 성도의 공진 특성으로 인 해 기본주파수에서 형성된 배음 중에서 몇 개의 강조되는 배음들을 말한다. 이러한 포먼트들 중 낮은 주파수 쪽에서부 터 제1포먼트, 제2포먼트, 제 3 포먼트 등으로 부른다. 모음의 식별에는 제 1,2 포먼트가 가장 크게 관계된다.

무게중심은 스펙트럼 각 주파수에서 가중치를 곱하고 전 체를 적분한 값을 에너지 총량으로 나눈 값이다. 이는 스펙 트럼에서의 주파수 평균을 말하는 척도로 이해된다. 왜도 (skewness)는 무게중심 아래쪽 스펙트럼 모양이 무게중심 위쪽 모양과 얼마나 다른지 측정하는 것으로 세 번째 중앙
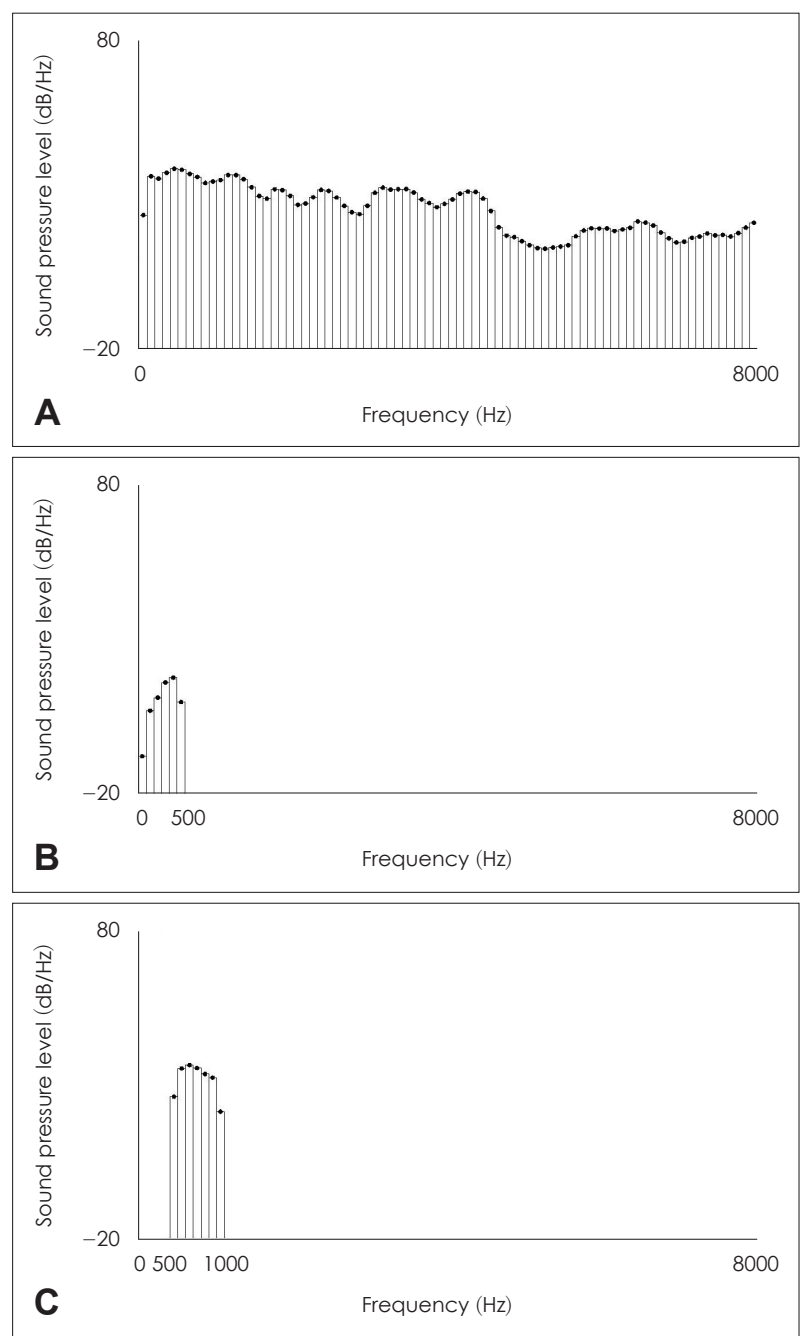

Fig. 1. LTAS slices of nasal sentence. LTAS slice of $0-8000 \mathrm{~Hz}$ (A). LTAS slice of $0-500 \mathrm{~Hz}$ (B). LTAS slice of $501-1000 \mathrm{~Hz}$. Minimum, maximum and slope was analyzed each slice (C). LTAS: long term average spectrum.

적률(moment)을 두 번째 중앙적률로 나눈 것으로 가우시아닝 정규분포(정규화된)에서 중앙부의 뾰족한 정도이며, 첨도 (kurtosis)는 스펙트럼의 좌우 치우침 양상을 의미하고, 중앙 적률(central moment)은 정규화되지 않은 왜도를 의미한다. 성대의 떨림에 의해 생기는 유성음은 성대에 의한 주기적인 펄스 형태로 나타나며 성대떨림 없이 나는 무성음에 비해 정 규분포에서 벗어나는 형태로 나타난다. 개개인 성대의 떨림 특성에 따라 정규분포에 비해 스펙트럼이 뾰족하게 나타나거 나 왼쪽 혹은 오른쪽으로 치우침이 발생하게 되며 개개인 목 소리의 음색을 결정짓는 중요한 요소로 작용한다. ${ }^{7)}$

\section{통계분석}

정상 성인과 비중격만곡증 환자 사이의 차이를 비교하기 위해 non-paired t-test를 사용하였고, 동일 환자의 수술 전 
후의 변화를 비교하기 위하여 paired t-test를 사용하였다. 통 계분석은 SPSS 20.0(SPSS Inc., Chicago, IL, USA)을 사용 하여 분석하였고 모든 결과값은 $p$ 값이 0.05 이하인 경우를 통계학적으로 유의한 것으로 판정하였다.

\section{결 과}

비강체적, 비저항, 비음치의 비교(Table 1)

음향통기도 검사(acoustic rhinometry)로 측정한 총 비강 체적(total nasal volume)은 대조군이 $21.72 \pm 4.39$, 환자군이 수술 전 17.05 \pm 5.33 , 수술 후 $21.98 \pm 3.70 \mathrm{~cm}^{3}$ 였다. 비강통기 도검사(rhinomanometry)로 측정한 흡기 시 총비저항(total nasal resistance)은 대조군이 $0.38 \pm 0.37$, 환자군이 수술 전 $0.95 \pm 0.50$, 수술 후 $0.49 \pm 0.39 \mathrm{~Pa} \mathrm{~s} / \mathrm{cm}^{3}$ 였고, 호기 시 총비저 항은 대조군이 $0.41 \pm 0.39$, 환자군이 수술 전 $1.03 \pm 0.46$, 수술 후 $0.67 \pm 0.57 \mathrm{~Pa} \mathrm{~s} / \mathrm{cm}^{3}$ 로 수술 전에 비해 수술 후에 총 비강 체적이 의미 있게 증가하고 비저항은 의미 있게 감소하는 것을 알 수 있다(Fig. 3).

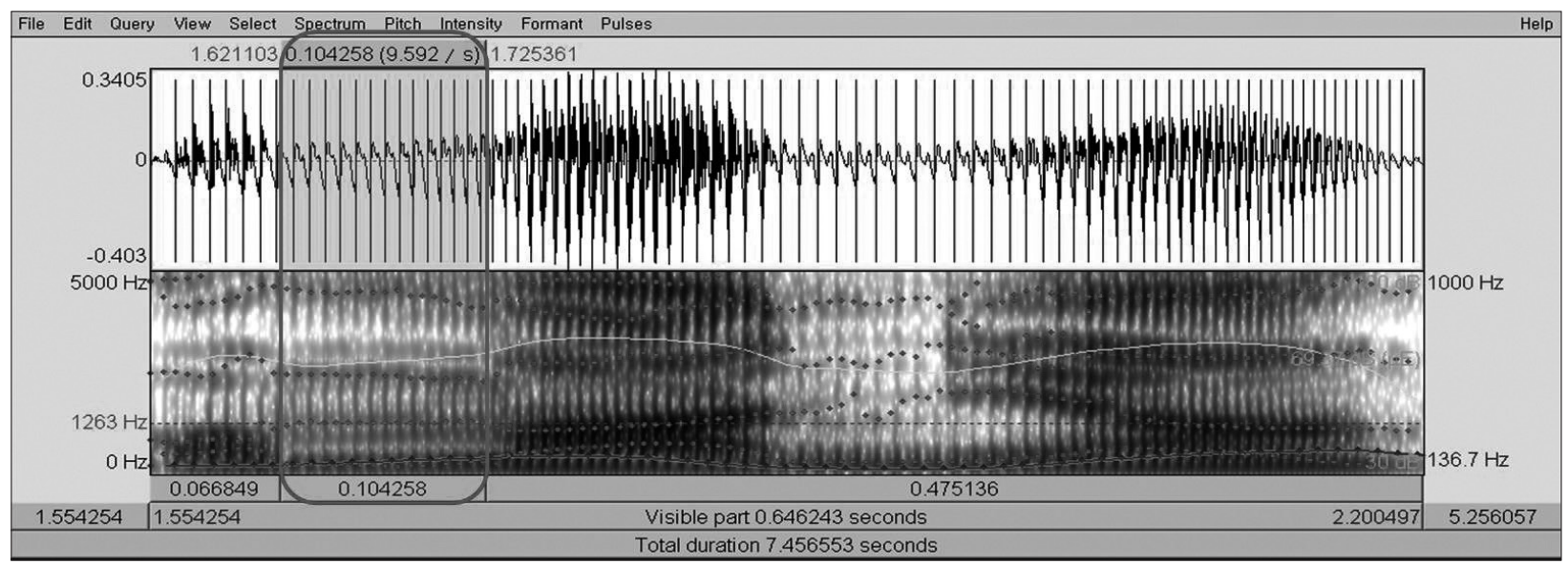

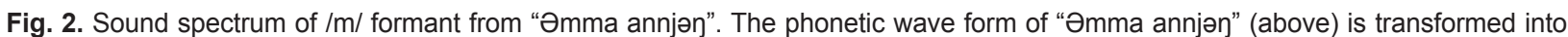
sound spectrum (below). Presents the formant of each corresponding consonant.
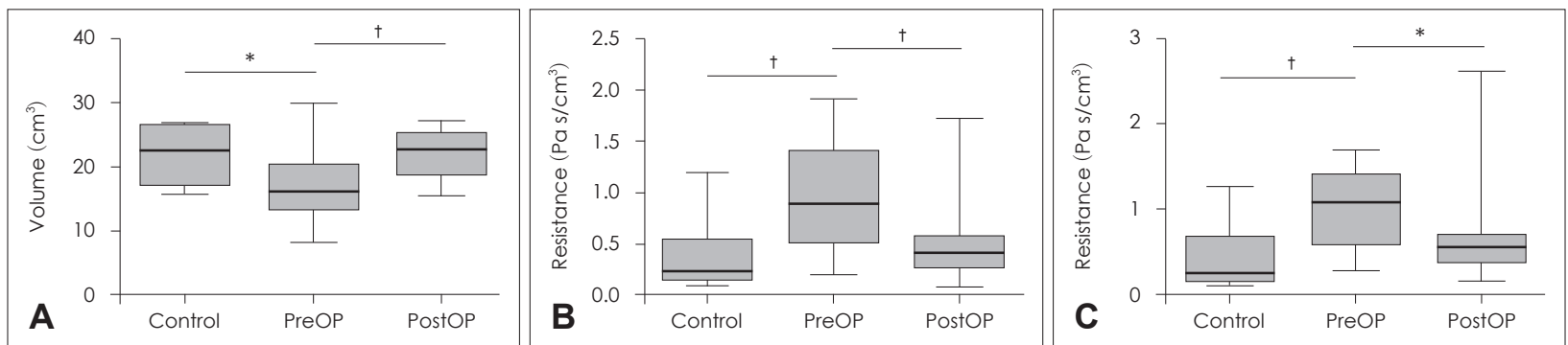

Fig. 3. Nasal cavity volume, resistance of groups. Nasal cavity volume of groups (control: $21.72 \pm 4.39$, preoperation: $17.05 \pm 5.33$, postoperation: $21.98 \pm 3.70 \mathrm{~cm}^{3}$ ) (A). Inspiratory resistance of groups (control: $0.38 \pm 0.37$, preoperation: $0.95 \pm 0.50$, postoperation: $0.49 \pm 0.39$ $\left.\mathrm{Pa} \mathrm{s} / \mathrm{cm}^{3}\right)(\mathrm{B})$. Expiratory resistance of groups (control: $0.41 \pm 0.39$, preoperatioin: $1.03 \pm 0.46$, postoperation: $\left.0.67 \pm 0.57 \mathrm{~Pa} s / \mathrm{cm}^{3}\right)(\mathrm{C})$. The difference between control and preOP $(*)$, preOP and postOP $(\dagger)$ was statistically siginificant.
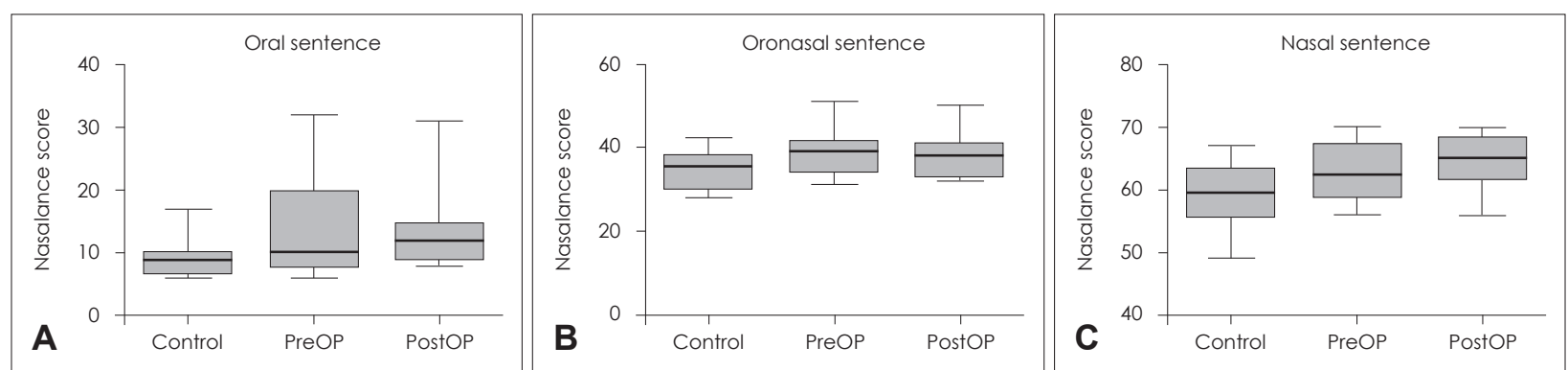

Fig. 4. Nasalance score of oral sentence (/Suhi kajogi padae katt'a. pedo thago thjubido thatt'a. kapłagi piga wasə cibiro tolawatt'a/control: $9.4 \pm 3.13$, preoperation: $13.88 \pm 7.87$, postoperation: $13.31 \pm 5.69 \%)(A)$. Nasalance score of oronasal sentence (/Onilin t $\varepsilon g o n w ə n e$ sophun kanin nalida. əmmaga kimbapt'o mandifjett'a. kwajaran sikhechibugiran kajjəgatt'a/control: $34.6 \pm 4.70$, preoperation: $38.5 \pm 4.72$,

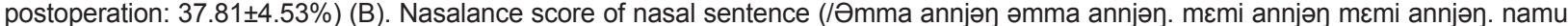
annjəク namu annjəク/control: $59.2 \pm 5.33$, preoperation: $62.88 \pm 4.54$, postoperation: $64.56 \pm 4.08 \%)(C)$. 
나조메타(nasometer)로 측정한 비음치는 구강음 문장의

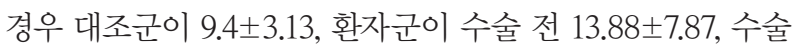
후 $13.31 \pm 5.69 \%$ 였고(Table 1), 대조군과 술 전 환자군, 술 전 과 술 후 환자군 간의 통계적 유의성은 발견할 수 없었다(Fig. 4A). 구강비음 문장의 경우 대조군이 $34.6 \pm 4.70$, 환자군이 수 술 전 $38.5 \pm 4.72$, 수술 후 $37.81 \pm 4.53 \%$ 였고 각 군 사이에 통 계적으로 의미 있는 차이는 보이지 않았다(Fig. 4B). 비음 문장 의 경우 대조군이 $59.2 \pm 5.33$, 환자군이 수술 전 $62.88 \pm 4.54$, 수술 후 64.56 $4.08 \%$ 였고, 비음 문장에서도 구강음 문장과 같이 대조군과 술 전 환자군, 술 전과 술 후 환자군 간의 통 계적 유의성은 발견할 수 없었다(Fig. 4C).

\section{수술 전후 Long term average spectrum의 변화}

비음 문장에 대한 주파수 대역별로 최소 에너지 gain, 최대

Table 2. Changes of long term average spectrum

\begin{tabular}{lccc}
\hline & Preoperative & Postoperative & p value \\
\hline Minimal gain $(\mathrm{dB})$ & & & \\
Total & $0.26 \pm 6.77$ & $-0.10 \pm 5.65$ & 0.6807 \\
Min 1 & $17.28 \pm 11.81$ & $18.41 \pm 10.46$ & 0.5369 \\
Min 2 & $27.54 \pm 2.67$ & $27.22 \pm 2.76$ & 0.6564 \\
Maximal gain (dB) & & & \\
Total & $37.57 \pm 2.98$ & $38.04 \pm 2.74$ & 0.3000 \\
Max 1 & $36.18 \pm 2.74$ & $36.74 \pm 2.85$ & 0.3125 \\
Max 2 & $34.80 \pm 2.52$ & $34.95 \pm 2.58$ & 0.6528 \\
Slope & & & \\
Total & $-4.43 \pm 3.33$ & $-5.47 \pm 3.38$ & 0.1165 \\
Slope 1 & $-194.14 \pm 5.97$ & $-189.27 \pm 6.75$ & $0.0247^{*}$ \\
Slope 2 & $-26.68 \pm 1.92$ & $-27.53 \pm 3.17$ & 0.2565 \\
\hline
\end{tabular}

*the slope $1(0-500 \mathrm{~Hz})$ was significant increased after operation $(p=0.0247)$. Min 1: minimal gain of $0-500 \mathrm{~Hz}$, Min 2: minimal gain of $500-1000 \mathrm{~Hz}$, Max 1: Maximal gain of $0-500 \mathrm{~Hz}$, Max 2: Maximal gain of $500-1000 \mathrm{~Hz}$, Slope 1: slope of $0-500$ $\mathrm{Hz}$, Slope 2: slope of $500-1000 \mathrm{~Hz}$
에너지 gain과 slope를 분석하였다. 그 결과 수술 전후로 0 $500 \mathrm{~Hz}$ 대역에서 기울기(slope1)가 통계적으로 의미 있게 증 가하는 양상을 보였다. 하지만 나머지 변수에 대해서는 의미 있는 차이를 보이지 않았다(Table 2).

\section{수술 전후 종성 자음 $/ \mathrm{m} /, / \mathrm{n} /, / \mathrm{ng} /$ 에 대한 음향적 요소의 분석}

종성 자음 $/ \mathrm{m} /$ 에 대한 스펙트럼을 분석한 결과 제 1 포먼트 에서 통계적으로 유의하게 주파수가 증가하는 것을 알 수 있 었다(Table 3). 무게중심 역시 통계적으로 유의하게 증가하였 다. 이외에 다른 변수에 대해서는 의미 있는 차이를 보이지 않 았다(Table 3).

종성 자음 $/ \mathrm{n} /$ 에 대한 스펙트럼을 분석한 결과 제 1 포먼트 에서 통계적으로 유의한 주파수대의 상승을 관찰할 수 있었 으며, 제1밴드윗드, 중앙적률 역시 통계적으로 유의하게 증가 하였다(Table 4). 그 외에 왜도, 첨도 또한 수술 후 유의하게 감 소하였다(Table 4).

종성 자음 $/ \mathrm{ng} /$ 에서는 수술 전후로 유의한 차이를 보이는 스펙트럼 분석 변수는 없었다(Table 5).

\section{고 찰}

음성이란 후두의 진동으로 생긴 에너지를 이용하여 성도에 서 구강과 인두강이 필터역할을 하여 생성되는 것이다. 성도 의 공진 특성으로 인해 기본주파수에서 형성된 배음 중에서 몇 개의 배음들은 강조되며 이런 높은 에너지를 가진 배음들 을 포먼트라 하며 이 음역대에 의해 음색이 달라지게 된다. ${ }^{8)}$

비음치는 비강 음향에너지를 비강과 구강의 전체 음향에너 지로 나눈 값을 의미하며, 비강이 음성공명에 중요한 역할을

Table 3. Spectrum analysis of final consonant $/ \mathrm{m} /$

\begin{tabular}{|c|c|c|c|}
\hline & Preoperative & Postoperative & $p$ value \\
\hline \multicolumn{4}{|l|}{ Formant $(\mathrm{Hz})$} \\
\hline $\mathrm{Fl}$ & $237.82 \pm 18.99$ & $249.37 \pm 15.52$ & $0.0452^{*}$ \\
\hline F2 & $1192.12 \pm 153.58$ & $1167.81 \pm 153.55$ & 0.4534 \\
\hline F3 & $2516.44 \pm 142.02$ & $2471.37 \pm 158.50$ & 0.1177 \\
\hline \multicolumn{4}{|l|}{ Band width $(\mathrm{Hz})$} \\
\hline BWl & $132.13 \pm 94.35$ & $128.60 \pm 90.92$ & 0.8913 \\
\hline BW2 & $458.42 \pm 413.25$ & $468.71 \pm 394.08$ & 0.9131 \\
\hline BW3 & $171.41 \pm 109.36$ & $201.38 \pm 118.25$ & 0.3686 \\
\hline Center of gravity $(\mathrm{Hz})$ & $196.01 \pm 21.58$ & $210.34 \pm 24.40$ & $0.0139 *$ \\
\hline Kurtosis & $1085.39 \pm 529.71$ & $1044.88 \pm 671.65$ & 0.8301 \\
\hline Skewness & $24.54 \pm 5.98$ & $23.84 \pm 7.03$ & 0.6935 \\
\hline Central moment & $110021361.9 \pm 53458392.85$ & $177773924.3 \pm 150490726$ & 0.0921 \\
\hline
\end{tabular}

* formant 1, center of gravity: statistically significant increased. F1: formant 1, F2: formant 2, F3: formant 3, BW1: band width 1, BW2: band width 2, BW3: band width 3 
Table 4. Spectrum analysis of final consonant $/ \mathrm{n} /$

\begin{tabular}{lccc}
\hline & Preoperative & Postoperative & p value \\
\hline Formant $(\mathrm{Hz})$ & & & $0.0307^{*}$ \\
F1 & $264.42 \pm 33.73$ & $319.04 \pm 92.70$ & 0.6321 \\
F2 & $1431.93 \pm 275.77$ & $1390.44 \pm 220.03$ & 0.8297 \\
F3 & $2524.14 \pm 336.12$ & $2551.96 \pm 256.15$ & \\
Band width (Hz) & & & $0.0031^{*}$ \\
BW1 & $112.14 \pm 43.72$ & $173.79 \pm 82.99$ & 0.4081 \\
BW2 & $725.24 \pm 479.55$ & $589.29 \pm 459.87$ & 0.8000 \\
BW3 & $438.71 \pm 381.22$ & $482.88 \pm 536.19$ & $0.0193^{*}$ \\
Center of gravity (Hz) & $199.18 \pm 24.22$ & $263.69 \pm 96.01$ & $0.0018^{*}$ \\
Kurtosis & $1160.57 \pm 473.34$ & $462.57 \pm 609.32$ & $0.0001^{*}$ \\
Skewness & $25.64 \pm 5.86$ & $15.12 \pm 7.44$ & $0.0046^{*}$ \\
Central moment & $134924633.9 \pm 78202760.99$ & $917224299.5 \pm 900117980$ & \\
\hline
\end{tabular}

* formant 1, band width 1, center of gravity, central moment: statistically significant increased. Skewness, Kurtosis: statistically significant decreased. F1: formant 1, F2: formant 2, F3: formant 3, BW1: band width 1, BW2: band width 2, BW3: band width 3

Table 5. Spectrum analysis of final consonant /ng/

\begin{tabular}{lccc}
\hline & Preoperative & Postoperative & P value \\
\hline Formant (Hz) & & & 0.5068 \\
F1 & $437.48 \pm 227.11$ & $400.50 \pm 151.16$ & 0.8895 \\
F2 & $1243.65 \pm 440.68$ & $1224.09 \pm 417.47$ & 0.1308 \\
F3 & $2590.85 \pm 234.59$ & $2508.99 \pm 229.84$ & \\
Band width (Hz) & & & 0.3866 \\
BW1 & $358.78 \pm 311.96$ & $313.06 \pm 178.14$ & 0.9503 \\
BW2 & $553.94 \pm 420.89$ & $546.37 \pm 434.73$ & 0.9436 \\
BW3 & $624.24 \pm 481.78$ & $611.94 \pm 568.78$ & 0.6770 \\
Center of gravity (Hz) & $264.63 \pm 66.96$ & $271.41 \pm 72.00$ & 0.3080 \\
Kurtosis & $269.82 \pm 179.87$ & $327.58 \pm 271.23$ & $11.98 \pm 6.15$ \\
Skewness & $10.97 \pm 5.04$ & $267621742 \pm 175566447$ & 0.3438 \\
Central moment & $302249563 \pm 247280685$ & 0.6413 \\
\hline
\end{tabular}

F1: formant 1, F2: formant 2, F3: formant 3, BW1: band width 1, BW2: band width 2, BW3: band width 3

하기 때문에 비중격 성형술 후 코막힘 증상이 개선될 경우 비 강으로의 기류량 증가로 비음치의 변화가 있을 것으로 예상 할 수 있다.

Dhong 등 ${ }^{4}$ 의 연구에서 부비동 내시경 수술 후 3개월 후에 측정한 비음치가 수술 전에 비해 증가하였는데, 특히, 구강비 음 문장과 비음 문장에서 통계적으로 유의한 증가가 있었다 고 보고하였다. 하지만, 객관적인 비강 체적의 변화나 비저항 의 측정은 이루어지지 않아 코막힘의 변화에 따른 비음치의 변화를 관찰하지 않았다. Hong 등 $^{2}$ 의 연구에서도 비음 문 장에 대한 비음치가 비부비동 수술 전에는 정상 대조군에 비 해 낮았지만 수술 후에는 정상 대조군 수준으로 비음치가 증 가하였다고 보고하였다. $\mathrm{Kim}$ 등 ${ }^{8)}$ 은 부비동 내시경 수술 후 비음형태, 스펙트럼 및 비부비동의 용적 변화를 분석하였고 술 후 1 개월째 측정한 스펙트럼 분석에서/ㅁ엥 대한 제1포 먼트가 유의한 감소를 보였다. 술 후 용적 변화와 제1포먼트 의 상관관계에 대한 분석도 시행하였고, 술 후 공명용적은 의
미 있는 증가를 보였으나 용적 증가 정도와 제1포먼트의 변화 정도 사이에는 유의한 상관관계를 알 수 없었다고 보고하였다.

또한 Birkent 등 ${ }^{9}$ 은 국소적 점막수축제를 이용한 비강용 적 변화와 비음치의 상관관계를 분석하였고, 비강의 크기, 비 기도 저항, 비기류, 구개인두 기능 등의 다양한 원인이 비음치 의 변화에 관여하기 때문에 상호 상관관계를 찾을 수 없다는 결론을 내렸다.

비중격 성형술 및 하비갑개 수술 후 비음치와 비음의 음향 학적 특성의 변화에 대한 연구는 상대적으로 적다. Jin 등5) 의 연구에 의하면 비중격 성형술 및 하비갑개 수술 후 비음 치는 수술 전에 비해 의미 있는 증가를 보이지 않았다. 하지 만, $\operatorname{Kim}$ 등 $^{1)}$ 과 Mora 등 ${ }^{10)}$ 의 연구에서는 비중격 성형술과 하 비갑개수술 후 1 개월째에는 술 전에 비해 비음치가 의미 있 게 증가함을 발견할 수 있었다. 하지만 $\mathrm{Kim}$ 등희의 연구에서 는 6개월 후에는 원래 수술 전의 상태로 다시 감소한다고 하 여 수술 후의 비음치 증가가 일시적인 현상이라고 하였다. 
본 연구에서 수술 전 후 의미 있는 비음치 변화는 관찰할 수 없었고, 이러한 결과는 실험군의 수의 부족과 수술 후 추 적 기간이 짧았기 때문에 나타난 현상으로 생각된다. 술 후 1 개월째에는 점막이 가피로 덮여 있고, 점막부종으로 인해 진 동이 저하되어 비음치가 증가하는 양상을 보이다가 시간이 지 나 점막이 회복됨에 따라 점차 정상 비음치에 가까워질 것으 로 생각해 볼 수 있다. 또한 술 전에 비폐색에 대해 보상적으 로 확장되었던 구개인두강이 수술 직후에 술 전과 비슷한 정 도로 유지되며 술 후 비강의 용적이 증가함에 따라 비음치의 증가를 보이다가 수술 후 시간이 지남에 따라 구개인두강 개 방에 의한 보상기전이 소실되며 수술 직후 나타난 과대비성 을 감소시키려는 방향으로 조절됨에 따라 $\mathrm{Kim}$ 등의 읜구결 과와 마찬가지로 의미 있는 차이가 없어질 수 있음을 예상할 수 있다.

비중격성형술 및 하비갑개 축소술 후 시간이 경과함에 따 라 음성의 변화가 없어지는 현상을 보이게 되는데 본 연구에 서는 수술 후 4주의 검사만 진행하였다. 장기간 추적관찰이 더 의미 있는 결과를 보여줄 수 있었을 것이라고 생각되나 현 실적으로 음성검사를 위한 장기간의 추적관찰이 어려웠던 점이 본 연구의 한계점으로 생각된다.

본 연구에서는 비중격성형술 및 하비갑개 축소술 전후의 비음치의 변화뿐만 아니라 비음치에 영향을 주는 주파수대 역을 알아보기 위해 비음 문장의 장구간평균스펙트럼 분석 (LTAS), 포먼트(formant), 밴드윗드(bandwidth), 적률분석 을 실시하였다. LTAS 분석결과 주파수대별 에너지 이득에는 수술 전후로 의미 있는 차이를 보이지 않았지만, 비음의 에너 지가 주로 존재하는 저 주파수대, 특히 0 500 Hz 구간에서 의 기울기가 통계적으로 유의한 차이를 보였다. 이것은 저주 파수 대역의 공명이 커져 비음과 관련된 음색의 변화가 생겼 음을 의미한다. 수술을 앞둔 환자들은 현재의 목소리가 수술 후에 어떤 변화를 일으키는 지에 대해 의문을 가지는 경우가 많다. 이런 환자들에게 비중격 및 하비갑개 성형술 후 비음 과 관련된 음색의 변화가 생기는 경향이 있고 시간이 지나면 서 수술 전과 비교하여 차이가 줄어들 수 있음을 설명할 수 있을 것으로 생각된다.

수술 전후 종성자음에 대한 스펙트럼 분석에서는 종성 $/ \mathrm{m} /$ 에서는 제1포먼트와 중앙적률이 통계적으로 의미 있게 주파 수가 증가하였고, $/ \mathrm{n} /$ 에서는 제 1 포먼트, 제 1 밴드윗드, 4 가지 적률변수가 의미 있는 차이를 보였지만, $/ \mathrm{ng} /$ 에서는 의미 있 는 차이를 보인 변수는 없었다. 종성 $/ \mathrm{m} /, / \mathrm{n} /$ 은 비강 앞쪽에
서 공명되고 종성 $/ \mathrm{ng} /$ 는 비강 뒤쪽에서 공명되는데, 비중격 성형술 및 하비갑개수술 후 종성 $/ \mathrm{m} /, \mathrm{ln} /$ 에서의 음향학적인 변화는 비강의 앞쪽의 개선도 변화와 관련이 있다고 할 수 있

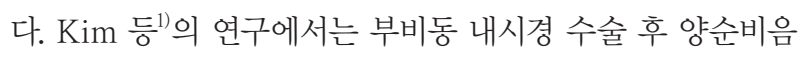
/ㅁ에서 제1포먼트의 유의한 감소를 보였으나 본 연구에서 는 비중격 성형술 및 하비갑개수술 후 $/ \mathrm{m} /$ 음에서 제 1 포먼트 의 증가를 알 수 있었는데 이것은 만성비부비동염 환자에서 의 비내시경수술은 상대적으로 비강의 뒤쪽의 용적과 비저 항에 대한 영향이 많기 때문에 상이한 결과가 도출되었다고 생각해 볼 수 있다. 따라서, 비부비동내시경 수술 후에 종성 $/ \mathrm{m} /, \mathrm{n} /$ 에 비해 종성 $/ \mathrm{ng} /$ 의 음향학적 변수의 변화가 더 많 이 생길지 관찰하는 연구는 흥미로울 것으로 생각되며 추후 이에 대한 연구가 필요할 것으로 사료된다.

\section{Acknowledgments}

This study was supported by 2015 Chungnam National University School Research Grant.

\section{REFERENCES}

1) Kim YH, Lee SH, Park CW, Cho JH. Nasalance change after sinonasal surgery: analysis of voice after septoturbinoplasty and endoscopic sinus surgery. Am J Rhinol Allergy 2013;27(1):67-70.

2) Hong KH, Kwon SH, Jung SS. The assessment of nasality with a nasometer and sound spectrography in patients with nasal polyposis. Otolaryngol Head Neck Surg 1997;117(4):343-8.

3) Soneghet R, Santos RP, Behlau M, Habermann W, Friedrich G, Stammberger H. Nasalance changes after functional endoscopic sinus surgery. J Voice 200216(3):392-7.

4) Dhong HJ, Kim SI, Kwon JK, Yun YS, Kang SM, Chu KC. Effects of endoscopic sinus surgery on nasality. Korean J OtolaryngolHead Neck Surg 1999;42(7):471-5.

5) Jin SM, Kang HG, Lee KC, Park SO, Lee SC, Lee YB. Significance of nasometer and first formant for nasal patency after septoplasty and turbinoplasty. J Korean Soc Logoped Phoniatr 1997;8(2):161-5.

6) Park M, Baek WS, Lee E, Koh KS, Kim BK, Baek R. Nasalance scores for normal Korean-speaking adults and children. J Plast Reconstr Aesthet Surg 2014;67(2):173-7.

7) Kang JH, Jeong SB. Speaker recognition performance improvement by voiced/unvoiced classification and heterogeneous feature combination. J Korea Inst Inf Commun Eng 2014;18(6):1294-301.

8) Kim CS, Kong SK, Lee HS, Cho KS, Wang SG, Roh HJ. Analysis of changes in nasal formant, spectra and resonant volume in rhinosinus after endoscopic sinus surgery. Korean J Otolaryngol-Head Neck Surg 2000;43(11):1208-15.

9) Birkent H, Erol U, Ciyiltepe M, Eadie TL, Durmaz A, Tosun F. Relationship between nasal cavity volume changes and nasalance. J Laryngol Otol 2009;123(4):407-11.

10) Mora R, Jankowska B, Dellepiane M, Mora F, Crippa B, Salami A. Acoustic features of voice after septoplasty. Med Sci Monit 2009; 15(6):CR269-73. 